\section{Comportamentos de risco para a saúde entre adolescentes em conflito com a lei}

\author{
Health risk behavior among young offenders
}

\section{Abstract}

The objective of this study was to investigate health risk behavior among teenage offenders committed to a social-educational institution in a city in Greater Metropolitan Recife, Pernambuco State, Brazil. The sample included 241 males 12-18 years of age. Data were collected with a brief self-completed questionnaire used by the Centers for Disease Control and Prevention, translated and adapted for young Brazilians. $79.7 \%$ of subjects reported having carried a gun and 52.7\% had been in fights involving physical aggression in the previous 12 months. Most of the young offenders smoked cigarettes (87.6\%) and consumed alcohol (64.7\%). The majority reported having sniffed inhalants (68.9\%), and 81.3\% had smoked marijuana. The vast majority (95.4\%) reported being sexually initiated, most having had sex with more than one partner. Young offenders showed high rates of various health risk behaviors.

Health Behavior; Adolescent; Social Behavior
Cláudia Alves de Sena ${ }^{1}$

Viviane Colares 2

\section{Introdução}

O adolescente sente a necessidade de confrontar, de experimentar limites, ou mesmo transgredilos, constituindo um espaço de conquista e de afirmação, que deve ser vivido individualmente ou em grupo. O desejo de ter experiências novas coexiste com o sentimento de invulnerabilidade e com o desejo de testar limites 1 .

Segundo a Organização Mundial da Saúde (OMS), a adolescência é o período compreendido entre 10 e 19 anos de idade. Do ponto de vista jurídico, adolescente é um indivíduo entre 12 anos completos e 18 anos incompletos, que se encontra em condição peculiar de desenvolvimento. E estar em conflito com a lei significa ser reconhecido como autor de ato infracional previsto no Código Penal 2.

Segundo o levantamento estatístico da Subsecretaria de Promoção dos Direitos da Criança e do Adolescente da Secretaria Especial de Direitos Humanos da Presidência da República, existiam em 2004 no Brasil cerca de 39.578 adolescentes no sistema sócio-educativo ${ }^{3}$. Em 2006, o número total de internos no sistema sócio-educativo de meio fechado no Brasil foi de 15.426 adolescentes, sendo a maioria (10.446) na internação, seguidos da internação provisória (3.746) e da semiliberdade (1.234) 4.

Em Pernambuco, 1.016 adolescentes estavam cumprindo medida sócio-educativa em regime de internação em setembro de 2006 4, o que cor- 
respondia a aproximadamente $8,21 \%$ da população de jovens no estado.

Segundo Assis \& Constantino ${ }^{5}$, alguns fatores podem ser considerados de risco, como ser do sexo masculino, apresentar determinadas características biológicas e psicológicas, como ter danos neurológicos sutis, impulsividade, hiperatividade, precário controle de frustrações, deficiência de atenção e incapacidade de planejamento e fixação de metas, assim como baixos níveis de inteligência. Ainda segundo esse autor, situações de negligência e de abandono, pobreza, criminalidade e violência na família, escola, comunidade e sociedade em geral são usuais entre adolescentes em conflito com a lei.

De acordo como o Estatuto da Criança e do Adolescente (ECA), o jovem acusado de prática de um ato infracional pode ficar internado provisoriamente em unidade especifica até que seja proferida a sentença referente ao seu processo. Essa internação provisória não pode exceder o período de 45 dias. Ao longo do processo, caso seja confirmada a prática do ato infracional e a necessidade de responsabilização do adolescente, o juiz poderá aplicar uma medida sócio-educativa, sendo a internação a mais rigorosa. A medida de privação de liberdade deve estar sujeita aos princípios da brevidade, excepcionalidade e respeito à condição peculiar da pessoa em desenvolvimento, em que em nenhuma hipótese pode ultrapassar três anos, devendo ser reavaliada a cada seis meses 6 .

Durante o período em que o adolescente estiver sob a tutela do Estado, deverão ser garantidos e respeitados diversos direitos previstos no ECA. Como forma de garantir tais direitos, em 14 de julho de 2004, foi instituída a Portaria Interministerial no. 1.426/GM7, que aprovou as diretrizes para implantação da Atenção à Saúde do Adolescente em Conflito com a Lei, que tem um elenco de ações no âmbito da promoção à saúde, prevenção de riscos e assistência aos agravos em unidades de internação e de internação provisória, garantindo a esses adolescentes a integralidade e universalidade de acesso aos serviços de saúde em todos os níveis de assistência, bem como uma atenção à saúde humanizada e de qualidade.

Diante dessas questões e da falta de informações com relação ao comportamento relacionado à saúde entre jovens em conflito com a lei, esse estudo teve como objetivo investigar as condutas de saúde entre adolescentes que se encontravam em sistema sócio-educativo de internação em Pernambuco, considerando comportamentos de risco, como situações de violência contra si e outros, consumo de substâncias, prática sexual precoce e desprotegida e outros que podem comprometer sua saúde.

\section{Métodos}

Esse estudo epidemiológico de corte transversal foi conduzido entre adolescentes em conflito com a lei, internos em instituição de atendimento sócio-educativo em um município da região metropolitana do Recife, Pernambuco, Brasil, que atende adolescentes que estão cumprindo pena em regime de privação de liberdade.

Em visita exploratória, observou-se superlotação na unidade investigada, assim como a presença de adolescentes fora da faixa etária determinada para aquela instituição, que seria de 12 a 17 anos. Os alojamentos são divididos em oito alas, distribuídas em torno de um pátio central, sendo cada ala com, em média, dez celas, que apresentam pouca ventilação e iluminação. De cinco a sete adolescentes são colocados em cada cela, onde ficam trancados e saem apenas para participarem de atividades físicas no pátio, ou para as atividades pedagógicas em sala de aula. A alimentação é servida no refeitório, e os adolescentes são acompanhados por funcionários da instituição sócio-educativa.

\section{Amostra}

De uma população de 285 internos do sexo masculino, concordaram em participar deste estudo 241 adolescentes $(84,26 \%)$, que compuseram a amostra. A maioria dos adolescentes tinha entre 16 e 18 anos de idade $(71,4 \%) ; 28,6 \%$ contavam entre 12 e 15 anos.

De acordo com informações fornecidas pelo Centro de Atendimento Sócio-educativo (CASE), ao chegar à instituição, 51,8\% tinham o ensino fundamental I e 41,4\% o Ensino Fundamental II incompletos, $5,8 \%$ eram analfabetos e $0,9 \%$ cursava o ensino médio. No CASE, os adolescentes estavam inseridos em atividades de ensino de acordo com sua escolaridade.

Quanto à procedência, 66\% eram da capital do estado, e $34 \%$ da região metropolitana do Recife e do interior. Com relação ao tempo de internamento, a maioria dos adolescentes estava na instituição pelo período de 6 a 12 meses ( $71,4 \%), 21,2 \%$ de 12 a 24 meses, $5 \%$ menor que 6 meses e 2,5\% por mais de 24 meses. Com relação ao ato infracional, grande parte havia praticado "roubo" (68\%), seguido de "porte ilegal de armas" (14,1\%), "furto" (9,5\%), "homicídio" (6,6\%), "latrocínio" (4,6\%), "estupro” (4,1\%) e "tráfico de drogas" (2,9\%). Deve-se ressaltar que o adolescente poderia estar relacionado a mais de um ato infracional. 


\section{Coleta dos dados}

Para a coleta dos dados, realizada entre agosto e outubro de 2006, foi utilizada uma versão reduzida do questionário de autopreenchimento utilizado pelo Centers for Disease Control and Prevention (CDC), dos Estados Unidos, para monitorar comportamentos de risco entre adolescentes americanos, traduzido e adaptado para adolescentes brasileiros por Carlini-Cotrim et al. 8 .

O questionário investiga as condutas relacionadas ao comportamento no trânsito; agressão contra si ou terceiros; consumo de substâncias tóxicas; consumo de álcool; comportamento sexual e controle de peso.

$\mathrm{O}$ instrumento foi aplicado de forma coletiva em sala de aula com um número máximo de seis adolescentes por vez. A pesquisadora fazia a leitura em voz alta de cada questão, solicitando em seguida que os adolescentes assinalassem suas respostas no questionário. Não era permitido o diálogo entre os pesquisados durante a leitura. Ao final, cada adolescente colocava seu questionário em um envelope único, garantindo o anonimato.

\section{Análise dos dados}

Para análise dos dados, foram utilizadas as técnicas de estatística descritiva e utilizado o teste do qui-quadrado de independência ou o teste exato de Fisher para verificar associações entre variáveis. Para a obtenção dos cálculos estatísticos, foram utilizados os programas SAS, versão 8 (SAS Inst., Cary, Estados Unidos). A margem de erro ou nível de significância utilizada na decisão dos testes estatísticos foi de $5 \%$.

Este estudo foi aprovado pelo Comitê de Ética da Universidade de Pernambuco.

\section{Resultados}

Entre os jovens pesquisados, $79,7 \%$ afirmaram ter portado arma, assim como $52,7 \%$ estiveram envolvidos em briga com agressão física nos 12 meses anteriores ao período de coleta de dados (Tabela 1).

Quanto à segurança no trânsito, verificou-se que entre aqueles que haviam andado de carro ou moto no último ano, apenas $35 \%$ e $39 \%$, respectivamente, afirmaram ter usado sempre o cinto de segurança e o capacete. E entre aqueles que haviam andado de carro nos últimos trinta dias, em torno de $20 \%$ pelo menos uma vez tinham sido com um motorista alcoolizado (Tabela 2).

Com relação ao suicídio, 22 jovens $(9,1 \%)$ afirmaram ter planejado cometê-lo no último ano, dentre eles, 16 tentaram o suicídio de fato e 4 necessitaram de cuidados médicos.

A maioria dos jovens já havia experimentado cigarro (87,6\%): $83 \%$ afirmaram ter fumado no último ano e $80,9 \%$, no último mês. A maioria dos jovens $(64,7 \%)$ afirmou ter consumido bebida alcoólica no último ano, porém apenas 21,6\% o fizeram no último mês (Tabela 3 ).

A maioria dos adolescentes $(68,9 \%)$ declarou já ter experimentado algum produto inalante na vida; $51,5 \%$ e $16,6 \%$ inalaram algum produto, respectivamente, nos últimos 12 meses e nos últimos 30 dias. Na Tabela 3 , pode-se verificar a companhia e o local onde os jovens fizeram uso de inalantes.

A maioria dos jovens (81,3\%) já havia experimentado maconha: $62,7 \%$ e $21,6 \%$ afirmaram ter fumado maconha nos últimos 12 meses e 30 dias, respectivamente.

A maioria dos adolescentes (56,8\%) afirmou ter recebido informações sobre AIDS, contudo apenas $30,7 \%$ já conversaram sobre o assunto com os pais ou outros adultos da família. Verificou-se que quase a totalidade dos jovens $(96,3 \%)$ já havia tido relação sexual, sendo a maioria com mais de um parceiro (Tabela 4). Entre aqueles que tinham tido relações sexuais, $64,7 \%$ informaram ter usado preservativo na ultima vez.

Com relação ao controle do peso corporal, os jovens declararam, majoritariamente, não ter feito dieta nos 12 meses anteriores à coleta de dados, tanto para perder quanto para ganhar peso (Tabela 4).

\section{Discussão}

A média de idade que concentra o maior número de adolescente em conflito com a lei é 15,8 anos. A média encontrada neste estudo está em consonância com a encontrada em outros estados do Brasil no levantamento nacional do atendimento sócio-educativo ao adolescente em conflito com a lei 4,9 .

A promoção de saúde entre adolescentes em conflito com a lei se torna um desafio, uma vez que a vida desses jovens é marcada pela violência, uso e/ou convivência com usuários de álcool ou outras drogas, além das dificuldades da própria adolescência que é um momento de adaptação ao processo de mudanças.

Poucos estudos se dedicam às condutas de saúde do adolescente em conflito com a lei. No Brasil, Miranda \& Zago 9, Peres et al. 10, Carvalho et al. 11 e Ferigolo et al. 12 avaliaram de forma isolada alguns comportamentos de risco entre esses jovens, como infecção pelo HIV e sífilis e uso de drogas. 
Caracterização da violência contra si e contra terceiros.

\begin{tabular}{|c|c|c|c|c|c|c|c|}
\hline \multirow[t]{3}{*}{ Variável } & \multicolumn{4}{|c|}{ Faixa etária (anos) } & \multicolumn{2}{|c|}{ Grupo total } & \multirow[t]{3}{*}{ Valor de $p$} \\
\hline & \multicolumn{2}{|c|}{$12-15$} & \multicolumn{2}{|c|}{$16-18$} & \multirow[b]{2}{*}{$\mathbf{N}$} & \multirow[b]{2}{*}{$\%$} & \\
\hline & $\mathbf{n}$ & $\%$ & $\mathbf{n}$ & $\%$ & & & \\
\hline \multicolumn{8}{|l|}{ Freqüência do porte de arma (revolver, faca ou pau) } \\
\hline Nenhuma & 14 & 20,3 & 35 & 20,3 & 49 & 20,3 & $p=0,282$ * \\
\hline $1 \mathrm{vez}$ & 12 & 17,4 & 35 & 20,3 & 47 & 19,5 & \\
\hline $2-3$ vezes & 9 & 13,0 & 22 & 12,8 & 31 & 12,9 & \\
\hline $4-5$ vezes & 2 & 2,9 & 13 & 7,6 & 15 & 6,2 & \\
\hline $6-7$ vezes & 3 & 4,3 & 5 & 2,9 & 8 & 3,3 & \\
\hline $8-9$ vezes & - & - & 1 & 0,6 & 1 & 0,4 & \\
\hline 10-11 vezes & 4 & 5,8 & 1 & 0,6 & 5 & 2,1 & \\
\hline 12 vezes ou + & 25 & 36,2 & 60 & 34,9 & 85 & 35,3 & \\
\hline Total & 69 & 100,0 & 172 & 100,0 & 241 & 100,0 & \\
\hline \multicolumn{8}{|l|}{ Envolvimento em briga com agressão física } \\
\hline Nenhuma & 36 & 52,2 & 78 & 45,3 & 114 & 47,3 & $p=0,964$ * \\
\hline 1 vez & 8 & 11,6 & 29 & 16,9 & 37 & 15,4 & \\
\hline $2-3$ vezes & 8 & 11,6 & 20 & 11,6 & 28 & 11,6 & \\
\hline $4-5$ vezes & 2 & 2,9 & 7 & 4,1 & 9 & 3,7 & \\
\hline 6-7 vezes & 1 & 1,4 & 4 & 2,3 & 5 & 2,1 & \\
\hline 8-9 vezes & 1 & 1,4 & 3 & 1,7 & 4 & 1,7 & \\
\hline 10-11 vezes & 2 & 2,9 & 3 & 1,7 & 5 & 2,1 & \\
\hline 12 vezes ou + & 11 & 15,9 & 28 & 16,3 & 39 & 16,2 & \\
\hline Total & 69 & 100,0 & 172 & 100,0 & 241 & 100,0 & \\
\hline \multicolumn{8}{|l|}{ Com quem brigou na última vez } \\
\hline Nunca entrou numa briga com agressão física & 32 & 46,4 & 74 & 43,0 & 106 & 44,0 & $p=0,476$ * \\
\hline Desconhecido & 17 & 24,6 & 37 & 21,5 & 54 & 22,4 & \\
\hline Alguém que conheço ou amigo(a) & 14 & 20,3 & 44 & 25,6 & 58 & 24,1 & \\
\hline Namorada & - & - & 2 & 1,2 & 2 & 0,8 & \\
\hline Pais, irmão, irmã ou outros familiares & 3 & 4,3 & 2 & 1,2 & 5 & 2,1 & \\
\hline Outras pessoas não citadas & 2 & 2,9 & 4 & 2,3 & 6 & 2,5 & \\
\hline Mais do que uma das pessoas citadas & 1 & 1,4 & 9 & 5,2 & 10 & 4,1 & \\
\hline Total & 69 & 100,0 & 172 & 100,0 & 241 & 100,0 & \\
\hline
\end{tabular}

* Através do teste exato de Fisher.

Neste estudo, avaliaram-se condutas de saúde buscando uma visão panorâmica da situação, de forma a identificar os comportamentos de risco mais freqüentes, visando fornecer informações que possibilitem uma abordagem mais objetiva.

Verificou-se que os comportamentos adotados pelos adolescentes, associados a um quadro precário quanto às condições físicas, materiais e humanas nas unidades de internação, assim como uma população acima de sua capacidade de atendimento, podem prejudicar o processo de crescimento e desenvolvimento desses jovens.

Este estudo revelou que a locomoção em bicicletas é uma prática comum dentre essa população $(88,8 \%)$, sendo realizada sem uso do capacete. $\mathrm{O}$ maior uso de capacete ao andar de moto
$(32,8 \%)$ foi relatado pelos jovens como estratégia de proteção contra reconhecimento por parte de outros na hora em que cometiam atos delitivos, ou seja, usam para não serem identificados em vez de usá-lo para a proteção da cabeça.

O fenômeno da violência, decorrente do envolvimento em brigas dentro e fora do ambiente escolar 13, é outro comportamento que coloca em risco a vida e a saúde dos adolescentes. Envolvimento em brigas com agressão física foi relatado pela maioria dos jovens pesquisados, cujos dados encontrados foram semelhantes aos de Carlini-Cotrim et al. 8 .

Os dados desse estudo indicaram que o porte de arma foi elevadíssimo (79,7\%), se comparado com escolares de São Paulo $(7,9 \%)$. 
Caracterização da amostra quanto ao comportamento no trânsito.

\begin{tabular}{|c|c|c|c|c|c|c|c|}
\hline \multirow[t]{3}{*}{ Variável } & \multicolumn{4}{|c|}{ Faixa etária (anos) } & \multicolumn{2}{|c|}{ Grupo total } & \multirow[t]{3}{*}{ Valor de p } \\
\hline & \multicolumn{2}{|c|}{$12-15$} & \multicolumn{2}{|c|}{$16-18$} & \multirow[b]{2}{*}{$\mathbf{N}$} & \multirow[b]{2}{*}{$\%$} & \\
\hline & n & $\%$ & $\mathrm{n}$ & $\%$ & & & \\
\hline \multicolumn{8}{|c|}{ Freqüência do uso cinto de segurança ao andar de carro } \\
\hline Não andou de carro nos últimos 12 meses & 9 & 13,0 & 24 & 14,0 & 33 & 13,7 & $p=0,829$ * \\
\hline Nunca & 12 & 17,4 & 27 & 15,7 & 39 & 16,2 & \\
\hline Raramente & 3 & 4,3 & 17 & 9,9 & 20 & 8,3 & \\
\hline Às vezes & 13 & 18,8 & 31 & 18,0 & 44 & 18,3 & \\
\hline A maioria das vezes & 10 & 14,5 & 22 & 12,8 & 32 & 13,3 & \\
\hline Sempre & 22 & 31,9 & 51 & 29,7 & 73 & 30,3 & \\
\hline Total & 69 & 100,0 & 172 & 100,0 & 241 & 100,0 & \\
\hline \multicolumn{8}{|c|}{ Freqüência do uso de capacete andando de motocicleta } \\
\hline Não andou de moto nos últimos 12 meses & 10 & 14,5 & 27 & 15,7 & 37 & 15,4 & $p=0,977$ * \\
\hline Nunca & 13 & 18,8 & 34 & 19,8 & 47 & 19,5 & \\
\hline Raramente & 6 & 8,7 & 11 & 6,4 & 17 & 7,1 & \\
\hline Às vezes & 13 & 18,8 & 28 & 16,3 & 41 & 17,0 & \\
\hline A maioria das vezes & 6 & 8,7 & 14 & 8,1 & 20 & 8,3 & \\
\hline Sempre & 21 & 30,4 & 58 & 33,7 & 79 & 32,8 & \\
\hline Total & 69 & 100,0 & 172 & 100,0 & 241 & 100,0 & \\
\hline \multicolumn{8}{|l|}{ Freqüência do uso de capacete andando de bicicleta } \\
\hline Não andou de bicicleta nos últimos 12 meses & 3 & 4,3 & 16 & 9,3 & 19 & 7,9 & 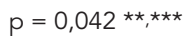 \\
\hline Nunca & 61 & 88,4 & 153 & 89,0 & 214 & 88,8 & \\
\hline Raramente & 1 & 1,4 & - & - & 1 & 0,4 & \\
\hline Às vezes & 2 & 2,9 & - & - & 2 & 0,8 & \\
\hline A maioria das vezes & - & - & - & - & - & - & \\
\hline Sempre & 2 & 2,9 & 3 & 1,7 & 5 & 2,1 & \\
\hline Total & 69 & 100,0 & 172 & 100,0 & 241 & 100,0 & \\
\hline \multicolumn{8}{|l|}{ Andar em carro dirigido por alguém } \\
\hline \multicolumn{8}{|l|}{ Que havia tomado bebida alcoólica } \\
\hline \multicolumn{8}{|l|}{ Nos últimos 30 dias } \\
\hline Não andou de carro nos últimos 30 dias & 31 & 44,9 & 85 & 49,4 & 116 & 48,1 & $p=0,469 * \star$ \\
\hline Nenhuma & 34 & 49,3 & 67 & 39,0 & 101 & 41,9 & \\
\hline $1 \mathrm{vez}$ & 1 & 1,4 & 8 & 4,7 & 9 & 3,7 & \\
\hline $2-3$ vezes & 2 & 2,9 & 5 & 2,9 & 7 & 2,9 & \\
\hline $4-5$ vezes & 1 & 1,4 & 2 & 1,2 & 3 & 1,2 & \\
\hline 6 vezes ou + & - & - & 5 & 2,9 & 5 & 2,1 & \\
\hline Total & 69 & 100,0 & 172 & 100,0 & 241 & 100,0 & \\
\hline
\end{tabular}

* Através do teste qui-quadrado de Pearson;

** Através do teste exato de Fisher;

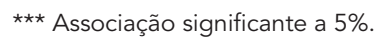

Com relação ao consumo de tabaco e álcool, os achados deste estudo indicaram que entre as drogas consideradas lícitas, a de maior consumo foi o tabaco $(87,6 \%)$, enquanto o álcool foi consumido por $64,7 \%$ dos adolescentes. Analisando a literatura sobre o tema, observa-se que o tabagismo é o principal fator de risco à saúde. Dados da OMS estimaram que no Brasil o número de fumantes é de 35 milhões e que, desse total, 3 milhões estão na faixa etária de 10 a 19 anos. Assis \& Souza 14 afirmaram, ainda, que quem começa a fumar nessa fase da vida tem mais chances de fumar por mais tempo.

Neste estudo, observou-se maior consumo de tabaco $(91,3 \%)$ entre os mais jovens. No entanto, outro estudo indicou que o uso do tabaco vem crescendo conforme a idade 15 . 
Distribuição dos jovens de acordo com o consumo de tabaco e álcool, e uso de inalantes.

\begin{tabular}{|c|c|c|c|c|c|c|c|}
\hline \multirow[t]{3}{*}{ Variável } & \multicolumn{4}{|c|}{ Faixa etária (anos) } & \multicolumn{2}{|c|}{ Grupo total } & \multirow[t]{3}{*}{ Valor de $p$} \\
\hline & \multicolumn{2}{|c|}{$12-15$} & \multicolumn{2}{|c|}{$16-18$} & \multirow[b]{2}{*}{$\mathbf{N}$} & \multirow[b]{2}{*}{$\%$} & \\
\hline & $\mathbf{n}$ & $\%$ & $\mathbf{n}$ & $\%$ & & & \\
\hline \multicolumn{8}{|l|}{ Experimentou cigarro na vida } \\
\hline $\operatorname{Sim}$ & 65 & 94,2 & 146 & 84,9 & 211 & 87,6 & $p=0,048 *, * \star$ \\
\hline Não & 4 & 5,8 & 26 & 15,1 & 30 & 12,4 & \\
\hline Total & 69 & 100,0 & 172 & 100,0 & 241 & 100,0 & \\
\hline \multicolumn{8}{|l|}{ Número de dias que fumou cigarro nos últimos 30 dias } \\
\hline Nenhum & 9 & 13,0 & 37 & 21,5 & 46 & 19,1 & $\mathrm{p}=0,731$ *** \\
\hline $1-2$ & 3 & 4,3 & 6 & 3,5 & 9 & 3,7 & \\
\hline $3-5$ & 2 & 2,9 & 6 & 3,5 & 8 & 3,3 & \\
\hline $6-9$ & 1 & 1,4 & 1 & 0,6 & 2 & 0,8 & \\
\hline $10-19$ & 3 & 4,3 & 8 & 4,7 & 11 & 4,6 & \\
\hline $20-29$ & 1 & 1,4 & 4 & 2,3 & 5 & 2,1 & \\
\hline 30 & 50 & 72,5 & 110 & 64,0 & 160 & 66,4 & \\
\hline Total & 69 & 100,0 & 172 & 100,0 & 241 & 100,0 & \\
\hline \multicolumn{8}{|l|}{ Consumo de bebida alcoólica nos últimos 12 meses } \\
\hline Nenhum dia & 17 & 24,6 & 68 & 39,5 & 85 & 35,3 & $\mathrm{p}=0,004 *, * *$ \\
\hline $1 \mathrm{dia}$ & 17 & 24,6 & 19 & 11,0 & 36 & 14,9 & \\
\hline 2 dias & 11 & 15,9 & 14 & 8,1 & 25 & 10,4 & \\
\hline 3-5 dias & 11 & 15,9 & 14 & 8,1 & 25 & 10,4 & \\
\hline 6-9 dias & 3 & 4,3 & 7 & 4,1 & 10 & 4,1 & \\
\hline 10-19 dias & 2 & 2,9 & 10 & 5,8 & 12 & 5,0 & \\
\hline 20 dias ou + & 8 & 11,6 & 40 & 23,3 & 48 & 19,9 & \\
\hline Total & 69 & 100,0 & 172 & 100,0 & 241 & 100,0 & \\
\hline \multicolumn{8}{|l|}{ Consumo de bebida alcoólica nos últimos 30 dias } \\
\hline Nenhum dia & 54 & 78,3 & 135 & 78,5 & 189 & 78,4 & $p=0,951 \star \star \star$ \\
\hline 1-2 dias & 11 & 15,9 & 22 & 12,8 & 33 & 13,7 & \\
\hline $3-5$ dias & 2 & 2,9 & 4 & 2,3 & 6 & 2,5 & \\
\hline 6-9 dias & 1 & 1,4 & 6 & 3,5 & 7 & 2,9 & \\
\hline 10-19 dias & - & - & 2 & 1,2 & 2 & 0,8 & \\
\hline 20-29 dias & - & - & 1 & 0,6 & 1 & 0,4 & \\
\hline 30 dias & 1 & 1,4 & 2 & 1,2 & 3 & 1,2 & \\
\hline Total & 69 & 100,0 & 172 & 100,0 & 241 & 100,0 & \\
\hline \multicolumn{8}{|l|}{ Companhia na última ocasião em que fez } \\
\hline \multicolumn{8}{|l|}{ uso de produto inalante } \\
\hline Nunca usou inalantes & 18 & 26,1 & 61 & 35,5 & 79 & 32,8 & 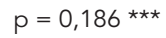 \\
\hline Estava sozinho, sem ninguém conhecido por perto & 13 & 18,8 & 31 & 18,0 & 44 & 18,3 & \\
\hline Estava com um amigo(a) & 33 & 47,8 & 71 & 41,3 & 104 & 43,2 & \\
\hline Estava com a namorada & 2 & 2,9 & 4 & 2,3 & 6 & 2,5 & \\
\hline Estava com pais, irmão ou outros parentes & 3 & 4,3 & 1 & 0,6 & 4 & 1,7 & \\
\hline Mais de uma alternativa & - & - & 4 & 2,3 & 4 & 1,7 & \\
\hline Total & 69 & 100,0 & 172 & 100,0 & 241 & 100,0 & \\
\hline \multicolumn{8}{|l|}{ Local onde você usou produto inalante na última ocasião } \\
\hline Nunca usou inalantes & 17 & 24,6 & 60 & 34,9 & 77 & 32,0 & $p=0,297 \star \star \star *$ \\
\hline Na rua, praça, terreno ou outro espaço público & 42 & 60,9 & 85 & 49,4 & 127 & 52,7 & \\
\hline Em casa, na casa de amigo(a) ou namorada & 7 & 10,1 & 12 & 7,0 & 19 & 7,9 & \\
\hline $\mathrm{Na}$ escola & - & - & 3 & 1,7 & 3 & 1,2 & \\
\hline Outros & 3 & 4,3 & 12 & 7,0 & 15 & 6,2 & \\
\hline Total & 69 & 100,0 & 172 & 100,0 & 241 & 100,0 & \\
\hline
\end{tabular}

* Associação significante a $5 \%$;

** Através do teste qui-quadrado de Pearson;

*** Através do teste exato de Fisher. 
Distribuição dos jovens de acordo com o número de parceiros sexuais, método para prevenir gravidez e caracterização do peso corporal da amostra.

\begin{tabular}{|c|c|c|}
\hline & $\mathbf{n}$ & $\%$ \\
\hline \multicolumn{3}{|l|}{ Atividade sexual } \\
\hline \multicolumn{3}{|c|}{ Na vida, com quantas pessoas você já teve relação sexual? } \\
\hline Nunca teve relação sexual & 9 & 3,7 \\
\hline 1 & 27 & 11,2 \\
\hline 2 & 24 & 10,0 \\
\hline 3 & 17 & 7,1 \\
\hline 4 & 18 & 7,5 \\
\hline 5 & 11 & 4,6 \\
\hline 6 ou + & 135 & 56,0 \\
\hline Total & 241 & 100,0 \\
\hline \multicolumn{3}{|c|}{ Método para prevenir a gravidez na última vez em que você teve relação sexual } \\
\hline Nunca manteve relação sexual & 9 & 3,7 \\
\hline Nenhum método foi usado & 71 & 29,5 \\
\hline Pílulas anticoncepcionais & 22 & 9,1 \\
\hline Preservativo ou camisinha & 101 & 41,9 \\
\hline Coito interrompido & 8 & 3,3 \\
\hline Outros métodos & 1 & 0,4 \\
\hline Não tenho certeza & 29 & 12,0 \\
\hline Total & 241 & 100,0 \\
\hline \multicolumn{3}{|l|}{ Caracterização do peso corporal } \\
\hline \multicolumn{3}{|c|}{ Descrição do corpo em relação ao peso } \\
\hline Muito gordo & 7 & 2,9 \\
\hline Um pouco gordo & 35 & 14,5 \\
\hline Não é gordo, nem magro & 119 & 49,4 \\
\hline Um pouco magro & 46 & 19,1 \\
\hline Muito magro & 34 & 14,1 \\
\hline Total & 241 & 100,0 \\
\hline \multicolumn{3}{|c|}{ O que vem tentando fazer em relação ao próprio peso } \\
\hline Perder peso & 14 & 5,8 \\
\hline Ganhar peso & 94 & 39,0 \\
\hline Manter o mesmo peso & 88 & 36,5 \\
\hline Não está tentando fazer nada & 45 & 18,7 \\
\hline Total & 241 & 100,0 \\
\hline \multicolumn{3}{|c|}{ Fez alguma dieta para perder ou para controlar o peso nos últimos 12 meses } \\
\hline Sim & 17 & 7,1 \\
\hline Não & 224 & 92,9 \\
\hline Total & 241 & 100,0 \\
\hline
\end{tabular}

Apesar de a legislação brasileira proibir a venda de bebidas alcoólicas e tabaco a menores de 18 anos, a maioria dos adolescentes não tem dificuldades para conseguir tais substâncias 12 .

A violência cresce a cada dia em todo o país e nos mais diversos locais, reflexo das diferenças sócio-econômicas que estabelecem relação entre violência e pobreza, vadiagem e marginalidade. Com isso, nota-se que o consumo de substâncias ilícitas utilizadas pelo adolescen- te antecede à internação em instituições sócio-educativas. Neste estudo, as drogas ilícitas investigadas foram os inalantes e a maconha, que apresentaram consumo elevado na vida dos internos: $68,9 \%$ e $81,3 \%$, respectivamente. Entre os inalantes, o "loló" e a "cola" foram os mais citados, a cola é a droga de iniciação dos adolescentes em conflito com a lei, seguida pela maconha. Ferigolo et al. 12 concluíram que o uso de drogas é parte de um problema de atos 
infracionais e de violência envolvendo crianças e adolescentes.

Na VIII Conferência Nacional de Saúde, realizada em 1986, considerou-se a saúde resultante das condições de alimentação, habitação, educação, renda, meio ambiente, transporte, emprego, lazer, liberdades, acesso à posse da terra e aos serviços de saúde. A falta dessas condições básicas talvez justifique os comportamentos adotados pelos adolescentes, em geral, de risco à saúde.

Os comportamentos sexuais de risco podem acarretar impacto na vida reprodutiva dos jovens, resultando em aquisição de doenças sexualmente transmissíveis como a infecção pelo HIV. A primeira relação sexual é considerada um marco na vida do individuo e observa-se que tem ocorrido cada vez mais precocemente. Essa antecipação da primeira relação sexual está presente em diferentes extratos sociais e é admitida como uma tendência generalizada.

A maioria dos adolescentes pesquisados relatou ter acesso a informações sobre os riscos da AIDS e estratégias para diminuir os riscos, todavia não adotaram práticas de sexo seguro. Neste estudo, verificou-se que 95,4\% dos adolescentes em conflito com a lei já tiveram relação sexual, e a maioria com mais de um parceiro, sendo considerado fator de risco para aquisição de HIV. Tais resultados são superiores aos encontrados em outros trabalhos 16 .

Entre os adolescentes com vida sexual ativa incluídos neste estudo, uma parcela significativa, $35,3 \%$, relatou não ter usado preservativo na última relação sexual. Peres et al. 10 afirmaram que o uso do preservativo ficou mais popular, e sua freqüência de uso cresceu entre os jovens desde 1993 em razão das campanhas educativas e da mídia. Acrescenta que, dentre os jovens de 16 a 25 anos de idade, $87 \%$ afirmaram usar camisinha conscientemente com parceiros casuais, $24 \%$, em todas as relações sexuais, e $90 \%$ declararam que não teriam relação sexual com alguém que conhecessem recentemente e se recusasse a usar o preservativo. A pesquisa de Peres et al. 10 ainda considerou que a relação entre o uso de drogas e comportamento sexual de risco é resultado de uma complexa confirmação de fatores culturais, comportamentais e circunstanciais.

Durante as visitas para a coleta de dados do presente estudo, foram obtidas algumas informações em conversas informais. Em relação à situação de violência, muitos jovens narraram a violência doméstica como rotineira. Em muitos casos, o pai ou a mãe encontrava-se privado de liberdade, por homicídio, roubo, tráfico de drogas, entre outros delitos. Evidencia-se um processo de desagregação familiar.

Ao se questionar o pensamento suicida, foram ouvidos comentários como: "que isso tia, a gente se matar? A gente pensa em matar os outros". Observando-se uma banalização da morte.

Com relação à prática sexual, os jovens queixaram-se pela ausência de visitas íntimas na unidade de internação. E com relação ao uso do preservativo, alguns apontaram a dificuldade de aquisição, fazendo uso de "saco de picolé" como substituto.

Mediante a análise dos resultados recomenda-se que sejam realizados outros estudos com a população de adolescentes em conflito com lei, internos em instituições brasileiras, assim como sejam implantados programas de intervenção para a promoção da saúde entre esses jovens que se encontram em situação de alto risco.

\section{Conclusão}

De um modo geral, os jovens em situação de conflito com a lei apresentaram vários comportamentos de risco para a saúde, relacionados com a violência, como porte de arma ou envolvimento em briga física. Observou-se também elevado consumo de tabaco e outras drogas; assim como prática sexual desprotegida.

O contexto sócio-educativo busca fornecer conhecimentos indispensáveis à vida social e estimular comportamentos aceitáveis, favorecendo a integração do indivíduo na sociedade. A educação para a saúde é um dos temas que deve ser contemplado nessa proposta, entre outros que visem à educação para comportamentos sociais. 


\section{Resumo}

O objetivo deste estudo foi investigar as condutas de saúde entre adolescentes em conflito com a lei, internos em instituição de atendimento sócio-educativo em município da região metropolitana do Recife, Pernambuco, Brasil. A amostra foi composta por 241 jovens do sexo masculino, de 12 a 18 anos de idade. Para a coleta de dados, utilizou-se uma versão reduzida do questionário de autopreenchimento utilizado pelo Centers for Disease Control and Prevention dos Estados Unidos, traduzido e adaptado para jovens brasileiros. Entre os jovens pesquisados, 79,7\% afirmaram ter portado arma, assim como 52,7\% estiveram envolvidos em briga com agressão física nos últimos 12 meses. Verificou-se que a maioria dos jovens pesquisados era usuário de tabaco (87,6\%) e álcool (64,7\%). Grande parte dos jovens afirmou já ter experimentado algum produto inalante na vida $(68,9 \%)$ e ter feito uso de maconha (81,3\%). A maioria dos jovens $(95,4 \%)$ já tinha tido relação sexual, em geral com mais de um parceiro. Os jovens em situação de conflito com a lei apresentaram vários comportamentos de risco à saúde em percentuais elevados.

Conduta de Saúde; Adolescente; Compoprtamento Social

\section{Referências}

1. Silva AS, Deus AF. Comportamentos de consumo de haxixe e saúde mental em adolescentes: estudo comparativo. Anál Psicol 2005; 2:151-72.

2. Brasil. Lei federal 8.069/90: disposição do estatuto da criança e do adolescente. Diário Oficial da União 1990; 13 jul.

3. Murad JGP, Arantes RS, Saraiva ALR. Levantamento estatístico sobre o sistema sócio-educativo. Brasília: Subsecretaria de Promoção dos Direitos da Criança e do Adolescente, Secretaria Especial dos Direitos Humanos, Presidência da República; 2004.

4. Secretaria Especial de Direitos Humanos. Levantamento nacional do atendimento sócio-educativo. Brasília: Secretaria Especial dos Direitos Humanos, Presidência da República; 2006.

5. Assis SG, Constantino P. Perspectivas de prevenção da infração juvenil masculina. Ciênc Saúde Coletiva 2005 ; 10:81-90.

6. Cury M, Silva AFA, Mendes EG, coordenadores. Estatuto da criança e do adolescente comentado: comentários jurídicos e sociais. São Paulo: Malheiros Editores; 2005.

7. Brasil. Portaria Interministerial $n^{\circ}$. $1.426 / \mathrm{GM}$, de 14 de julho de 2004: atenção à saúde do adolescente em conflito com a lei. Diário Oficial da União 2004; 15 jul.

8. Carlini-Cotrim B, Gazal-Carvalho C, Gouveia N Comportamentos de saúde entre jovens estudantes das redes pública e privada da área metropolitana do Estado de São Paulo. Rev Saúde Pública 2000; 34:636-45.

\section{Colaboradores}

C. A. Sena concebeu e planejou o estudo, levantou os dados, analisou e interpretou os resultados e redigiu o texto. V. Colares revisou o texto, contribuiu no planejamento do estudo, na análise e interpretação dos resultados.
9. Miranda AE, Zago AM. Prevalência de infecção pelo HIV e sífilis em sistema correcional para adolescentes. DST J Bras Doenças Sex Transm 2001; 13:35-9.

10. Peres CA, Paiva V, Silveira F, Peres RA, Hearst N. Prevenção da AIDS com adolescentes encarcerados em São Paulo. Rev Saúde Pública 2002; 36:76-81.

11. Carvalho HB, Seibel SD, Burattini MN, Massad E, Reingold A. Vulnerabilidade às infecções pelo HIV, hepatites B e C e sífilis entre adolescentes infratores institucionalizados na cidade de São Paulo. DST J Bras Doenças Sex Transm 2003; 15:41-5.

12. Ferigolo M, Barbosa FS, Arbo E, Malysz AS, Stein AT, Barros HMT. Prevalência do consumo de drogas na FEBEM de Porto Alegre. Rev Bras Psiquiatr 2004; 26:10-6.

13. Abramovay M. Escola e violência. Brasília: Organização das Nações Unidas para a Educação, a Ciência e a Cultura; 2002.

14. Assis SG, Souza ER. Criando Caim e Abel: pensando na prevenção juvenil. Ciênc Saúde Coletiva 1999; 4:131-44.

15. Horta BL, Calheiros P, Pinheiro RT, Tomasi E, Amaral KC. Tabagismo em adolescentes de área urbana na região Sul do Brasil. Rev Saúde Pública 2001; 35:159-64.

16. Rigato FD. Descrição do perfil sócio-demográfico e avaliação de comportamento de risco de crianças e adolescentes atendidos pelo projeto Quixote [Dissertação de Mestrado]. São Paulo: Universidade de São Paulo; 2002.

Recebido em 11/Set/2007

Versão final reapresentada em 28/Jan/2008 Aprovado em 28/Mar/2008 